\title{
Embebição de sementes de soja em solução de fosfato de potássio(1)
}

\author{
Claudia Antonia Vieira Rossetto(2), Lorena Kaufmann ${ }^{(3)}$, Jorge Jacob-Neto(4) e Avílio Antonio Franco ${ }^{(5)}$
}

Resumo - O experimento foi realizado com o objetivo de estudar a possibilidade de aumentar a concentração de fósforo e de potássio nas sementes de soja (Glycine max (L.) Merrill), cv. EMBRAPA 66, utilizando três métodos de embebição (contato com substrato úmido, imersão em solução e imersão em solução a vácuo) e as concentrações de $\mathrm{KH}_{2} \mathrm{PO}_{4}$ : 0, 50, 100, 150 e $200 \mathrm{mM}$. O delineamento experimental foi inteiramente casualizado, em esquema fatorial (métodos de embebição x concentrações de solução), com quatro repetições. As determinações dos conteúdos de $\mathrm{P}$ e $\mathrm{K}$ nas sementes e as avaliações de germinação e vigor foram realizadas imediatamente após o procedimento e após a secagem. Os métodos da imersão e da imersão a vácuo proporcionam 14\% de acúmulo de $\mathrm{P}$ nas sementes de soja. Os métodos de embebição e as concentrações de $\mathrm{KH}_{2} \mathrm{PO}_{4}$ não aumentamo teor de $\mathrm{K}$ das sementes de soja. $\mathrm{O}$ método do substrato úmido provoca menor prejuízo à qualidade fisiológica inicial das sementes. A secagem das sementes acentua os danos causados pelos métodos de imersão e imersão a vácuo.

Termos para indexação: Glycine max, semente, absorção de nutrientes, métodos.

\section{Soybean seeds imbibition in potassium phosphate solution}

\begin{abstract}
The experiment was carried out to study the possibility to increase the phosphorus and potassium contents in soybean seeds (Glycine max (L.) Merrill) cv. EMBRAPA 66, using three methods of soaking (moist substrate, immersion and immersion under vacuum) and the $\mathrm{KH}_{2} \mathrm{PO}_{4}$ concentrations: $0,50,100,150$ and $200 \mathrm{mM}$. The experimental design was a factorial (methods of soaking $\mathrm{x}$ $\mathrm{KH}_{2} \mathrm{PO}_{4}$ concentrations) replicated four times. Phosphorus and potassium contents, seed vigor and germination were determined just after soaking and after drying at room conditions. Soaking the seeds in immersion and immersion under vacuum resulted in $14 \%$ increase in the $\mathrm{P}$ concentration in the soybean seeds. The methods of soaking and $\mathrm{KH}_{2} \mathrm{PO}_{4}$ concentrations did not increase the $\mathrm{K}$ concentrations in the soybean seeds. Soaking the seeds in moist substrate caused less damage to their physiological quality. Drying the seeds accentuates the damages caused by the imbibition methodology.
\end{abstract}

Index terms: Glycine max, seed, nutrient uptake, methods.

(1) Aceito para publicação em 28 de setembro de 2001. Apresentado no I Congresso Brasileiro de Soja, Londrina, PR, 1999. Financiado pela Faperj.

(2) Universidade Federal Rural do Rio de Janeiro (UFRRJ), Instituto de Agronomia (IA), Dep. de Fitotecnia, Caixa Postal 74511, CEP 23851-970 Seropédica, RJ. Bolsista do CNPq. E-mail: cavrosse@ufrrj.br

(3) UFRRJ, IA, Dep. de Fitotecnia. Bolsista do Pibic/CNPq. E-mail:1kfonseca@bol.com.br

(4)UFRRJ, IA, Dep. de Fitotecnia. E-mail: jorge@ufrrj.br

(5) Embrapa-Centro Nacional de Pesquisa de Agrobiologia, Caixa Postal 74505, CEP 23851-970 Seropédica, RJ. Bolsista do CNPq. E-mail: avilio@enpab.embrapa.br

\section{Introdução}

O aumento da concentração de nutrientes na semente tem sido obtido por meio da adubação no solo e da pulverização foliar, ou seja, da aplicação à planta-mãe (Jacob-Neto \& Rossetto, 1998). Todavia, estão sendo realizados estudos, visando obter mais uma possibilidade de aumento do conteúdo de nutrientes minerais, pela aplicação diretamente às sementes, via peletização (Sfredo et al., 1997) ou via embebição destas em soluções contendo determinados nutrientes (Teixeira, 1995; Teixeira et al., 1999). 
Em relação ao P, elemento indispensável para a obtenção de bons rendimentos, têm sido realizados vários experimentos com adubação no solo (Teixeira et al., 1999). No entanto, Zang et al. (1990) observaram, em plantas de cevada, cujo teor de $\mathrm{P}$ das sementes foi aumentado através da embebição, o efeito benéfico na acumulação de matéria seca e no alongamento da parte aérea.

Em feijão, a imersão das sementes, por duas horas, em solução de $100 \mathrm{mM}$ de $\mathrm{KH}_{2} \mathrm{PO}_{4}$, aumentou nelas o conteúdo de $\mathrm{P}$, favorecendo o crescimento da raiz primária, o número de nódulos e o peso dos grãos (Teixeira, 1995). Além disso, observou-se maior acúmulo na semente do íon fosfato em relação ao íon potássio, com o aumento da concentração de solução.

Trigo et al. (1997), avaliando sementes de soja com concentrações de $\mathrm{P}$, na faixa de 0,58 a $1,10 \%$, verificaram que o incremento da concentração desse nutriente na semente aumentou o rendimento de grãos da planta subseqüente, e o efeito benéfico da alta concentração de $\mathrm{P}$ na semente foi mais pronunciado em solos com alta disponibilidade deste elemento. Apesar disso, os níveis críticos tanto de $\mathrm{P}$ como de $\mathrm{K}$ nas sementes de soja ainda não foram estabelecidos.

$\mathrm{O} P$ é um dos mais importantes elementos no processo de fixação biológica de N (FBN), pois age especificamente durante o crescimento e no funcionamento dos nódulos (Graham \& Rosas, 1979; Israel, 1987). Em relação ao K, apesar de sua reconhecida importância no crescimento e desenvolvimento das plantas, sua atuação no processo de FBN não é conhecida (Clarkson, 1985). Sendo assim, o conteúdo de P e de K nas sementes pode ser importante na fase inicial de crescimento das plantas, quando o sistema radicular está pouco desenvolvido para o suprimento adequado da planta com esses nutrientes.

O objetivo deste trabalho foi estudar a possibilidade de aumentar a concentração de fósforo e potássio em sementes de soja (Glycine max (L.) Merrill), por embebição.

\section{Material e Métodos}

O ensaio foi realizado no Laboratório de Sementes, do DF/IA/UFRRJ, em Seropédica, RJ, em 1998. As sementes de soja, da cultivar EMBRAPA 66, foram submetidas à determinação dos teores de nutrientes iniciais (Embrapa, 1979; Malavolta et al., 1989), cujos resultados foram $6,0 \mathrm{mg} / \mathrm{g}$ de $\mathrm{Pe} 10,1 \mathrm{mg} / \mathrm{g}$ de $\mathrm{Ke}$ e, à avaliação da qualidade fisiológica inicial, através dos testes de germinação (Brasil, 1992) e de vigor (Marcos Filho et al., 1987), obtendo-se os seguintes resultados: $87 \%$ de germinação e $75 \%$ de plântulas normais na primeira contagem.

As sementes foram submetidas a três métodos de embebição $\left(1^{\circ}\right.$ - contato com substrato úmido; $2^{\circ}$ - imersão em solução; $3^{\circ}$ - imersão em solução, a vácuo), empregando cinco concentrações de $\mathrm{KH}_{2} \mathrm{PO}_{4}: 0,50,100,150 \mathrm{e}$ $200 \mathrm{mM}$, com potencial osmótico de $-0,245 \mathrm{MPa}$, $-0,491 \mathrm{MPa},-0,736 \mathrm{MPa}$ e -0,891 MPa, respectivamente. A pressão osmótica das soluções foi calculada pela fórmula proposta por Van Hóff (Jones Junior, 1983): $\psi o s=$ m.i.R.T., onde: $\psi$ os é o potencial osmótico; m, o número de moles; i, a correção devido à ionização do sal (constante de dissociação do produto multiplicado pelo número de íons fornecido pelo sal); $\mathrm{R}$, a constante dos gases $(0,0823 \mathrm{~atm})$; e $\mathrm{T}$, a temperatura em graus Kelvin. O delineamento experimental empregado foi inteiramente casualizado, em esquema fatorial (métodos de embebição $\mathrm{x}$ concentrações de $\mathrm{P}$ e de $\mathrm{K}$ na forma de $\mathrm{KH}_{2} \mathrm{PO}_{4}$ na solução), com quatro repetições.

Para cada método, o período de embebição, necessário para que as sementes atingissem 30 a $40 \%$ de água, foi definido pelas equações obtidas em cada concentração de $\mathrm{KH}_{2} \mathrm{PO}_{4}$ (Figura 1). Na elaboração destas curvas de absorção de água, foi realizado o monitoramento do grau de umidade, utilizando quatro amostras de 50 sementes, previamente avaliadas quanto ao teor inicial de água das sementes, conforme Rossetto et al. (1997a).

No tratamento de embebição em contato com substrato úmido, 50 sementes foram colocadas entre duas camadas de três folhas de papel toalha, marca Germitest, umedecido com soluções de $\mathrm{KH}_{2} \mathrm{PO}_{4}$ e, em seguida, acondicionadas em caixas plásticas transparentes $(11 \times 11 \times 3 \mathrm{~cm})$ e mantidas no germinador a $25^{\circ} \mathrm{C}$, durante 12 horas. No tratamento de imersão, 50 sementes foram imersas em $20 \mathrm{~mL}$ das soluções de $\mathrm{KH}_{2} \mathrm{PO}_{4}$, no interior de copos plásticos durante 40 minutos, sob a temperatura de $25^{\circ} \mathrm{C}$. No tratamento de imersão a vácuo, 50 sementes foram imersas em $20 \mathrm{~mL}$ das soluções de $\mathrm{KH}_{2} \mathrm{PO}_{4}$, em copos de $50 \mathrm{~mL}$ e submetidas à pressão de vácuo de $60 \mathrm{~mm}$ de $\mathrm{Hg}$ $(0,789 \mathrm{~atm})$, durante 12 minutos.

Foi realizada a avaliação da eficiência dos métodos de embebição, visando à adição de $\mathrm{P}$, através da determinação dos teores de nutrientes e da análise da qualidade fisiológica das sementes. Para isso, as sementes foram divididas em duas amostras: a primeira, foi avaliada imediatamente após o emprego dos métodos de embebição, e a 
segunda, após a secagem das mesmas em condições ambientais, até que as sementes atingissem o teor de água inicial, que foi confirmado pelo teste de grau de umidade (Brasil, 1992).

Na determinação do conteúdo de $\mathrm{P}$, duas repetições de 50 sementes foram submetidas à secagem em estufa por 72 horas à temperatura de $65^{\circ} \mathrm{C}$. A seguir, amostras de $0,200 \mathrm{~g}$ foram moídas e submetidas à digestão nitroperclórica e à dosagem colorimétrica em meio sulfomolíbdico, usando ácido ascórbico como redutor
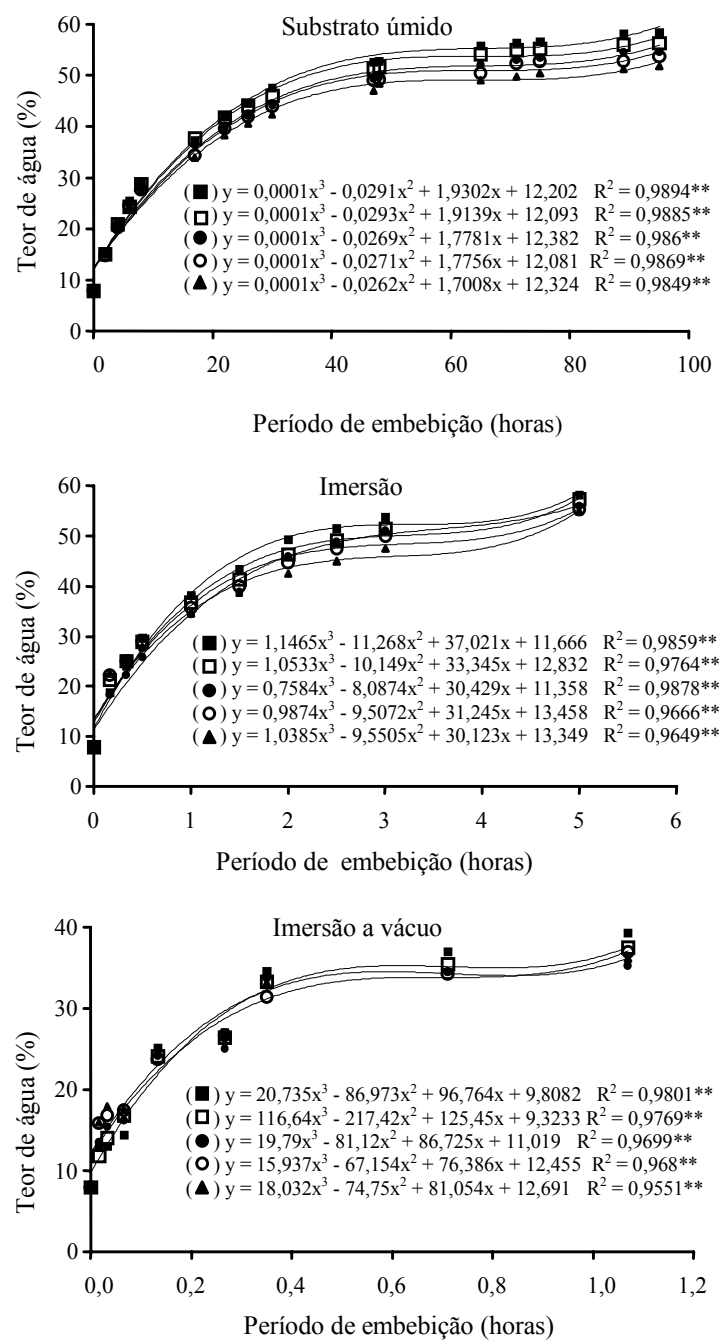

Figura 1. Teor de água das sementes de soja da cultivar EMBRAPA 66, após embebição em soluções de $0(\boldsymbol{\square})$, 50 (口), 100 (О), 150 (О) e $200 \mathrm{mM}(\boldsymbol{\Delta})$ de $\mathrm{KH}_{2} \mathrm{PO}_{4}$, pelos três métodos de embebição. Seropédica, 1998.
(Embrapa, 1979; Malavolta et al., 1989). Os teores de K foram determinados no fotômetro de chama (Embrapa, 1979).

$\mathrm{Na}$ avaliação da qualidade físiológica, foram utilizadas quatro repetições de 50 sementes nos testes de germinação (Brasil, 1992) e de vigor, avaliados através da condutividade elétrica da solução e da primeira contagem, conforme Marcos Filho et al. (1987).

O teste de germinação sob estresse hídrico, também considerado como teste de vigor, foi realizado somente nas sementes que foram submetidas aos métodos de embebição em soluções de 0, 100 e $200 \mathrm{mM}$ de $\mathrm{K}_{2} \mathrm{HPO}_{4}$. Para tanto, quatro repetições de 50 sementes foram colocadas para hidratar em papel-toalha, tipo Germitest, umedecido com soluções de polietilenoglicol (PEG 6000), preparadas com base na equação de Michel \& Kaufmann (1973), visando à obtenção de potenciais osmóticos de -0,3 MPa e -0,6 MPa (condições de deficiências hídricas), conforme Santos et al. (1992). A avaliação da porcentagem de plântulas normais nestas condições foi efetuada após sete dias da instalação.

Para a análise de variância, os dados em porcentagem foram previamente transformados em $(\mathrm{x}+1)^{0,5}$, mas os valores apresentados nas tabelas são os originais. As médias foram comparadas pelo teste de Tukey, a 5\% de probabilidade, e os dados de teor de água foram submetidos à análise de regressão.

\section{Resultados e Discussão}

O padrão de absorção de água pelas sementes submetidas aos três métodos foi semelhante ao padrão trifásico (Bewley \& Black, 1985), como evidenciado pelas equações (Figura 1). Com o aumento do período de embebição, houve redução do teor de água absorvido pelas sementes que foram submetidas às maiores concentrações de $\mathrm{KH}_{2} \mathrm{PO}_{4}$.

Quando foi realizada a avaliação imediatamente após os tratamentos, não houve efeito significativo da interação entre concentração de $\mathrm{KH}_{2} \mathrm{PO}_{4}$ e método de embebição no teor de $\mathrm{P}$ das sementes (Tabela 1). O menor acúmulo de $\mathrm{P}$ foi obtido quando as sementes foram submetidas à embebição pelo método do substrato, independentemente da concentração de $\mathrm{KH}_{2} \mathrm{PO}_{4}$. À medida que foi aumentando a concentração da solução de $\mathrm{KH}_{2} \mathrm{PO}_{4}$, independentemente do método de embebição, houve incremento do conteúdo de $\mathrm{P}$ das sementes. Embora a partir da concentração de 100 mM não tenha havido diferen- 
ças significativas, o maior aumento do conteúdo de $\mathrm{P}$ foi de $18 \%$, em relação ao conteúdo inicial desse nutriente da semente $(6,0 \mathrm{mg} / \mathrm{g})$. Comparando com os valores de P da semente de soja (5,8 a 11,0 mg/g), que foram encontrados por Trigo et al. (1997), podese inferir que há dificuldade de se aumentar o teor de $\mathrm{P}$ das sementes, a partir destes valores iniciais, conforme também relatado por Jacob-Neto \& Rossetto (1998). Assim, trabalhos que visam aumentar a concentração de $\mathrm{P}$ de sementes, via embebição ou pulverização foliar (Teixeira, 1995; Teixeira et al., 1999), devem considerar o potencial genético das sementes na acumulação de nutrientes. O mesmo pode ser aplicado ao $\mathrm{K}$.

No caso do K, na avaliação realizada imediatamente após o tratamento, verificou-se que ocorreu maior acúmulo deste nutriente, em torno de $12 \%$, apenas quando as sementes foram submetidas a embebição em solução de $100 \mathrm{mM}$ de $\mathrm{KH}_{2} \mathrm{PO}_{4}$, pelo método da imersão a vácuo; no entanto, não ocorreu diferença significativa em relação ao método do substrato úmido.
Na avaliação realizada após a secagem, o menor acúmulo de $\mathrm{P}$ foi obtido quando as sementes foram submetidas a embebição em solução de $200 \mathrm{mM}$ de $\mathrm{KH}_{2} \mathrm{PO}_{4}$, pelo método do substrato úmido; no entanto, não ocorreu diferença significativa em relação ao método da imersão. Em relação ao conteúdo de K, não houve efeito do método de embebição e da concentração da solução.

Houve efeito significativo da interação entre a concentração da solução e o método de embebição na qualidade fisiológica inicial das sementes $(87 \%$ de germinação e $75 \%$ de plântulas normais na primeira contagem) (Tabela 2). Na avaliação realizada imediatamente após os tratamentos, o método do substrato úmido foi o que causou menor prejuízo à germinação das sementes, que apresentaram, assim, os maiores valores. Quando as sementes foram expostas em contato com o substrato umedecido com solução a partir de $150 \mathrm{mM}$ de $\mathrm{KH}_{2} \mathrm{PO}_{4}$, cujo potencial osmótico está na faixa de $-0,736$ e $-0,891 \mathrm{MPa}$, houve diminuição da germinação. Rossetto et al.

Tabela 1. Dados médios de conteúdo de fósforo e potássio, obtidos após a embebição das sementes de soja, cultivar

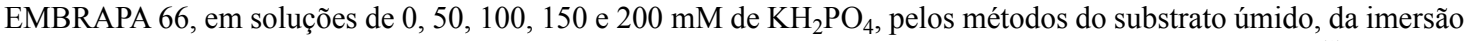
e da imersão a vácuo, logo após os tratamentos e após a secagem das sementes tratadas. Seropédica, 1998 ${ }^{(1)}$.

\begin{tabular}{|c|c|c|c|c|c|c|c|c|}
\hline \multirow{2}{*}{$\begin{array}{c}\mathrm{KH}_{2} \mathrm{PO}_{4} \\
(\mathrm{mM})\end{array}$} & \multicolumn{4}{|c|}{ Fósforo $(\mathrm{mg} / \mathrm{g})$} & \multicolumn{4}{|c|}{ Potássio (mg/g) } \\
\hline & $\begin{array}{c}\text { Substrato } \\
\text { úmido }\end{array}$ & Imersão & $\begin{array}{l}\text { Imersão a } \\
\text { vácuo }\end{array}$ & Média & $\begin{array}{l}\text { Substrato } \\
\text { úmido }\end{array}$ & Imersão & $\begin{array}{l}\text { Imersão a } \\
\text { vácuo }\end{array}$ & Média \\
\hline & \multicolumn{8}{|c|}{ Imediatamente após os tratamentos } \\
\hline 0 & 6,35 & 6,15 & 6,05 & $6,18 \mathrm{c}$ & $9,55 \mathrm{Aa}$ & $9,15 \mathrm{Aa}$ & $10,55 \mathrm{Aa}$ & 9,08 \\
\hline 50 & 6,15 & 6,40 & 6,75 & $6,43 \mathrm{bc}$ & $9,95 \mathrm{Aa}$ & $9,75 \mathrm{Aa}$ & $11,10 \mathrm{Aa}$ & 10,27 \\
\hline 100 & 6,75 & 6,95 & 7,05 & $6,92 \mathrm{abc}$ & $10,15 \mathrm{ABa}$ & $9,60 \mathrm{Ba}$ & $11,50 \mathrm{Aa}$ & 10,42 \\
\hline 150 & 6,40 & 7,70 & 7,50 & $7,20 \mathrm{ab}$ & $10,50 \mathrm{Aa}$ & $10,50 \mathrm{Aa}$ & $11,50 \mathrm{Aa}$ & 10,83 \\
\hline 200 & 6,50 & 7,80 & 7,65 & $7,32 \mathrm{a}$ & $10,90 \mathrm{Aa}$ & $11,70 \mathrm{Aa}$ & $11,90 \mathrm{Aa}$ & 11,50 \\
\hline \multirow[t]{2}{*}{ Média } & $6,43 \mathrm{~B}$ & $7,00 \mathrm{~A}$ & $7,00 \mathrm{~A}$ & & 10,21 & 10,14 & 11,51 & \\
\hline & \multicolumn{8}{|c|}{ Após a secagem } \\
\hline 0 & $6,35 \mathrm{Aa}$ & $6,20 \mathrm{Aa}$ & $6,15 \mathrm{Ab}$ & 6,23 & $10,15 \mathrm{Aa}$ & $10,50 \mathrm{Aa}$ & $10,90 \mathrm{Aa}$ & 10,52 \\
\hline 50 & $6,15 \mathrm{Aa}$ & $6,50 \mathrm{Aa}$ & $6,75 \mathrm{Aab}$ & 6,47 & $10,35 \mathrm{Aa}$ & $10,55 \mathrm{Aa}$ & $11,70 \mathrm{Aa}$ & 10,87 \\
\hline 100 & $6,55 \mathrm{Aa}$ & $6,85 \mathrm{Aa}$ & 7,35Aab & 6,92 & $10,35 \mathrm{Aa}$ & $11,10 \mathrm{Aa}$ & $11,70 \mathrm{Aa}$ & 11,05 \\
\hline 150 & $6,35 \mathrm{Aa}$ & $7,35 \mathrm{Aa}$ & $7,45 \mathrm{Aab}$ & 7,05 & $10,15 \mathrm{Aa}$ & $11,50 \mathrm{Aa}$ & $11,90 \mathrm{Aa}$ & 11,18 \\
\hline 200 & $6,15 \mathrm{Ba}$ & $7,60 \mathrm{ABa}$ & $8,05 \mathrm{Aa}$ & 7,27 & $11,30 \mathrm{Aa}$ & $12,10 \mathrm{Aa}$ & $12,30 \mathrm{Aa}$ & 11,90 \\
\hline Média & 6,31 & 6,90 & 7,15 & & 10,46 & 11,15 & 11,70 & \\
\hline
\end{tabular}


(1997b), avaliando o efeito da embebição das sementes de soja em substrato umedecido com solução de polietilenoglicol, verificaram que os potenciais hídricos de -0,20 e de -0,40 MPa causaram redução da emissão de raiz primária e da germinação.

Em relação ao vigor, o método do substrato úmido foi o que causou menor prejuízo à porcentagem de plântulas normais na primeira contagem, apresentando os maiores valores, como também foi observado em relação à germinação. Estes resultados sugerem que o método do substrato úmido provoca menor dano fisiológico às sementes. Quando as sementes foram expostas ao método do substrato úmido, a maior porcentagem de plântulas normais foi observada na concentração de $50 \mathrm{mM}$ de $\mathrm{KH}_{2} \mathrm{PO}_{4}$.

Comparando as avaliações realizadas imediatamente após as técnicas de embebição e após a secagem, observou-se que o processo de desidratação das sementes acentuou a diminuição da germinação e da porcentagem de plântulas normais na primeira contagem. As informações sobre o efeito da secagem na germinação, devido aos diferentes procedimentos de secagem, utilizados normalmente nos trabalhos científicos, dificultam a comparação dos resultados obtidos (Braccini et al., 1997).

$\mathrm{Na}$ avaliação realizada imediatamente após a aplicação dos tratamentos, o método do substrato úmido foi o que causou menor prejuízo ao vigor das sementes, avaliado pelo menor valor de condutividade elétrica da solução de embebição das sementes (Tabela 3). No entanto, não ocorreu diferença significativa entre os valores obtidos com o emprego do método do substrato úmido e da imersão a vácuo, quando foram empregadas as soluções de 100 e $150 \mathrm{mM}$. De acordo com Tao (1978), o teste de condutividade elétrica avalia os danos por embebição, ou seja, a quantidade de exsudatos liberados pelas sementes durante a embebição, e está relacionado à germinação (Pollock, 1969; Powell, 1986).

No presente trabalho, estes resultados podem estar relacionados com o grau de suscetibilidade das sementes de soja à injúria provocada pela rápida embebição das sementes expostas aos métodos de imersão e imersão a vácuo, que causaram prejuízo à

Tabela 2. Dados médios de germinação e plântulas normais na primeira contagem (vigor) obtidos após a embebição das sementes de soja cultivar EMBRAPA 66, em soluções de 0, 50, 100, 150 e $200 \mathrm{mM}^{2} \mathrm{KH}_{2} \mathrm{PO}_{4}$, pelos métodos do substrato úmido, da imersão e da imersão a vácuo, logo após os tratamentos e após a secagem das sementes tratadas. Seropédica, $1998^{(1)}$.

\begin{tabular}{|c|c|c|c|c|c|c|c|c|}
\hline \multirow{2}{*}{$\begin{array}{c}\mathrm{KH}_{2} \mathrm{PO}_{4} \\
(\mathrm{mM})\end{array}$} & \multicolumn{4}{|c|}{ Germinação (\%) } & \multicolumn{4}{|c|}{ Plântulas normais na primeira contagem (\%) } \\
\hline & $\begin{array}{l}\text { Substrato } \\
\text { úmido }\end{array}$ & Imersão & $\begin{array}{l}\text { Imersão a } \\
\text { vácuo }\end{array}$ & Média & $\begin{array}{c}\text { Substrato } \\
\text { úmido }\end{array}$ & Imersão & $\begin{array}{l}\text { Imersão a } \\
\text { vácuo }\end{array}$ & Média \\
\hline & \multicolumn{8}{|c|}{ Imediatamente após os tratamentos } \\
\hline 0 & $90,00 \mathrm{Aa}$ & $36,00 \mathrm{Cc}$ & $73,00 \mathrm{Ba}$ & 66,30 & $66,00 \mathrm{Ab}$ & $27,00 \mathrm{Cbc}$ & $56,00 \mathrm{Ba}$ & 49,70 \\
\hline 50 & $92,00 \mathrm{Aa}$ & $50,00 \mathrm{Cab}$ & $69,00 \mathrm{Ba}$ & 70,30 & $86,00 \mathrm{Aa}$ & $34,00 \mathrm{Cb}$ & $58,00 \mathrm{Ba}$ & 59,30 \\
\hline 100 & $88,00 \mathrm{Aa}$ & $61,00 \mathrm{Ba}$ & $61,00 \mathrm{Cb}$ & 65,70 & $68,00 \mathrm{Ab}$ & $50,00 \mathrm{Ba}$ & $37,00 \mathrm{Cb}$ & 51,70 \\
\hline 150 & $85,00 \mathrm{Aab}$ & $51,00 \mathrm{Bab}$ & $51,00 \mathrm{Bbc}$ & 60,70 & $67,00 \mathrm{Ab}$ & $27,00 \mathrm{Bbc}$ & $34,00 \mathrm{Bb}$ & 42,70 \\
\hline 200 & $77,00 \mathrm{Ab}$ & $43,00 \mathrm{Bbc}$ & $43,00 \mathrm{Bc}$ & 48,30 & $47,00 \mathrm{Ac}$ & $24,00 \mathrm{Bc}$ & $20,00 \mathrm{Bc}$ & 30,30 \\
\hline Média & 86,40 & 48,20 & 59,40 & & 66,80 & 32,40 & 41,00 & \\
\hline & \multicolumn{8}{|c|}{ Após a secagem } \\
\hline 0 & $74,00 \mathrm{Aa}$ & $18,00 \mathrm{Bb}$ & $25,00 \mathrm{Ba}$ & 39,00 & $56,00 \mathrm{Aa}$ & $15,00 \mathrm{Bb}$ & $15,00 \mathrm{Ba}$ & 28,70 \\
\hline 50 & $77,00 \mathrm{Aa}$ & $34,00 \mathrm{Ba}$ & $17,00 \mathrm{Cab}$ & 42,70 & $58,00 \mathrm{Aa}$ & $31,00 \mathrm{Ba}$ & $7,00 \mathrm{Cbc}$ & 32,00 \\
\hline 100 & $79,00 \mathrm{Aa}$ & $44,00 \mathrm{Ba}$ & $18,00 \mathrm{Cab}$ & 47,00 & $63,00 \mathrm{Aa}$ & $31,00 \mathrm{Ba}$ & $9,00 \mathrm{Cbc}$ & 34,30 \\
\hline 150 & $73,00 \mathrm{Aa}$ & $17,00 \mathrm{Bbc}$ & $20,00 \mathrm{Ba}$ & 36,70 & $59,00 \mathrm{Aa}$ & $11,00 \mathrm{Bb}$ & $12,00 \mathrm{Bab}$ & 27,30 \\
\hline 200 & $71,00 \mathrm{Aa}$ & $9,00 \mathrm{Bc}$ & $10,00 \mathrm{Bb}$ & 30,00 & $55,00 \mathrm{Aa}$ & $5,00 \mathrm{Bc}$ & $5,00 \mathrm{Bc}$ & 21,70 \\
\hline Média & 74,80 & 24,40 & 18,00 & & 58,20 & 18,60 & 9,60 & \\
\hline
\end{tabular}

${ }^{(1)}$ Médias seguidas de mesma letra, maiúscula na linha e minúscula na coluna, não diferem entre si, pelo teste de Tukey, a 5\% de probabilidade; os coeficientes de variação em relação a germinação e a plântulas normais na primeira contagem, na avaliação realizada imediatamente após o tratamento da embebição, foram de $6,87 \%$ e $6,61 \%$ e, após a secagem, de $9,59 \%$ e $9,25 \%$, respectivamente. 
germinação (Tabela 2). Para Tilden \& West (1985), o dano provocado pela embebição rápida seria a principal causa da redução da capacidade germinativa das sementes de algumas espécies sensíveis, pois é a velocidade de reorganização do sistema de membranas que reflete o vigor das sementes. A rápida embebição das sementes pode ser prejudicial devido à redução da integridade das membranas celulares, provocando perda de nutrientes essenciais e o aumento da atividade de microrganismos em função da liberação de solutos (Woodstock, 1988; Armstrong \& McDonald, 1992). Rossetto et al. (1997a), pelo teste de condutividade elétrica, também constataram que a diminuição da velocidade de embebição fez com que as sementes sofressem menor dano por embebição.

Quando foi realizada a avaliação após a secagem, não houve efeito significativo da interação entre concentração de $\mathrm{KH}_{2} \mathrm{PO}_{4}$ e método de embebição na condutividade elétrica (Tabela 3). O maior vigor, ava-

Tabela 3. Dados médios de condutividade elétrica obtidos após a embebição das sementes de soja, da cultivar EMBRAPA 66, em soluções de 0, 50, 100, 150 e 200 mM de $\mathrm{KH}_{2} \mathrm{PO}_{4}$, pelos métodos do substrato úmido, da imersão e da imersão a vácuo. Avaliações realizadas logo após o procedimento e após a secagem das sementes tratadas. Seropédica, $1998^{(1)}$.

\begin{tabular}{ccccc}
\hline $\mathrm{KH}_{2} \mathrm{PO}_{4}$ & \multicolumn{4}{c}{ Condutividade elétrica $(\mu \mathrm{S} / \mathrm{cm} / \mathrm{g})$} \\
\cline { 2 - 5 }$(\mathrm{mM})$ & $\begin{array}{c}\text { Substrato } \\
\text { úmido }\end{array}$ & Imersão & \multicolumn{1}{c}{$\begin{array}{l}\text { Imersão } \\
\text { a vácuo }\end{array}$} & Média \\
\hline \multicolumn{5}{c}{ Imediatamente após o tratamento de embebição } \\
0 & $56,08 \mathrm{Ba}$ & $84,68 \mathrm{Abc}$ & $80,42 \mathrm{Ab}$ & 73,72 \\
50 & $60,72 \mathrm{Ba}$ & $85,16 \mathrm{Abc}$ & $80,36 \mathrm{Ab}$ & 75,08 \\
100 & $63,35 \mathrm{Ba}$ & $100,78 \mathrm{Aab}$ & $77,87 \mathrm{Bb}$ & 80,66 \\
150 & $64,78 \mathrm{Ba}$ & $105,98 \mathrm{Aa}$ & $82,05 \mathrm{Bb}$ & 84,27 \\
200 & $67,51 \mathrm{Ba}$ & $111,36 \mathrm{Aa}$ & $107,83 \mathrm{Aa}$ & 95,56 \\
\hline Média & 62,48 & 97,39 & 85,70 \\
\hline \multicolumn{5}{c}{ Após a secagem } \\
0 & 58,32 & 74,96 & 64,42 & $65,90 \mathrm{~b}$ \\
50 & 64,19 & 81,86 & 62,37 & $69,48 \mathrm{~b}$ \\
100 & 66,88 & 88,84 & 82,03 & $79,25 \mathrm{a}$ \\
150 & 66,81 & 97,00 & 83,86 & $82,56 \mathrm{a}$ \\
200 & 68,14 & 98,06 & 87,96 & $82,56 \mathrm{a}$ \\
\hline Média & $64,87 \mathrm{C}$ & $88,14 \mathrm{~A}$ & $76,13 \mathrm{~B}$ \\
\hline
\end{tabular}

(1)Médias seguidas de mesma letra, maiúscula na linha e minúscula na coluna, não diferem entre si, pelo teste de Tukey, a 5\% de probabilidade; o coeficiente de variação em relação à avaliação realizada imediatamente após o tratamento da embebição foi de $8,31 \%$ e, após a secagem, de $6,77 \%$. liado pela menor condutividade elétrica, foi obtido quando as sementes foram submetidas ao método do substrato úmido, independentemente da concentração de $\mathrm{KH}_{2} \mathrm{PO}_{4}$. À medida que foi aumentando a concentração da solução de $\mathrm{KH}_{2} \mathrm{PO}_{4}$, independentemente do método de embebição, houve aumento da condutividade elétrica, embora a partir da concentração de 100 mM não tenha havido diferença significativa.

As sementes sob potencial osmótico de -0,30 $\mathrm{MPa}$, quando expostas às soluções de $\mathrm{KH}_{2} \mathrm{PO}_{4}$, pelos métodos da imersão e imersão a vácuo, apresentaram acentuada redução de germinação (Tabela 4), assim como também foi observado sob situação padrão (Tabela 2). Para Santos et al. (1992), o estresse hídrico até o potencial de -1,2 MPa quase não afeta a germinação das sementes de soja que apresentam maior vigor e não chega a inibir a germinação daquelas com menor vigor. As sementes, ao serem submetidas ao potencial osmótico de $-0,30 \mathrm{MPa}$, foram reduzindo acentuadamente a germinação, e sob potencial de -0,6 MPa não germinaram.

Tabela 4. Dados médios de germinação, sob estresse hídrico (-0,30 e -0,60 MPa), obtidos após a embebição das sementes de soja, da cultivar EMBRAPA 66, em soluções de 0,100 e $200 \mathrm{mM}$ de $\mathrm{KH}_{2} \mathrm{PO}_{4}$, pelos métodos do substrato úmido, da imersão e da imersão a vácuo. Avaliações realizadas logo após o procedimento. Seropédica, $1998^{(1)}$.

\begin{tabular}{ccccc}
\hline $\begin{array}{c}\mathrm{KH}_{2} \mathrm{PO}_{4} \\
(\mathrm{mM})\end{array}$ & $\begin{array}{c}\text { Substrato } \\
\text { úmido }\end{array}$ & Imersão & $\begin{array}{c}\text { Imersão } \\
\text { a vácuo }\end{array}$ & Média \\
\cline { 2 - 5 } & \multicolumn{5}{c}{$-0,30 \mathrm{MPa}$} \\
0 & $52,00 \mathrm{Aa}$ & $\begin{array}{c}46,00 \mathrm{Ba} \\
31,00 \mathrm{Ca}\end{array}$ & 33,00 \\
100 & $49,00 \mathrm{Aa}$ & $29,00 \mathrm{Bb}$ & $17,00 \mathrm{Cb}$ & 21,67 \\
200 & $43,00 \mathrm{Aa}$ & $27,00 \mathrm{Bb}$ & $10,00 \mathrm{Cc}$ & 26,67 \\
\hline Média & 48,00 & 17,33 & 16,00 \\
\hline \multicolumn{5}{c}{$-0,60 \mathrm{MPa}$} \\
0 & $2,00 \mathrm{Aa}$ & $0,00 \mathrm{Aa}$ & $0,00 \mathrm{Aa}$ & 0,67 \\
100 & $0,00 \mathrm{Aa}$ & $0,00 \mathrm{Aa}$ & $0,00 \mathrm{Aa}$ & 0,00 \\
200 & $1,00 \mathrm{Aa}$ & $0,00 \mathrm{Aa}$ & $0,00 \mathrm{Aa}$ & 0,33 \\
\hline Média & 1,00 & 0,00 & 0,00 \\
\hline \multicolumn{5}{c}{}
\end{tabular}

(1)Médias seguidas de mesma letra, maiúscula na linha e minúscula na coluna, não diferem entre si, pelo teste de Tukey, a 5\% de probabilidade; os coeficientes de variação em relação à germinação sob estresse hídrico de $-0,30$ e - $0,60 \mathrm{MPa}$ foram, respectivamente, de 13,26 e $29,01 \%$. 


\section{Conclusões}

1. Os métodos da imersão e da imersão a vácuo proporcionam $14 \%$ de acúmulo de fósforo nas sementes de soja.

2. Os métodos de embebição e as concentrações de $\mathrm{KH}_{2} \mathrm{PO}_{4}$ não aumentam o teor de potássio das sementes de soja.

3. O método do substrato úmido provoca menor prejuízo à qualidade fisiológica inicial das sementes.

4. A secagem das sementes acentua os danos causados pelos métodos de imersão e imersão a vácuo.

\section{Referências}

ARMSTRONG, H.; McDONALD, M. B. Effects of osmoconditioning on water uptake and electrical conductivity in soybean seeds. Seed Science and Technology, Zurich, v. 20, n. 3, p. 391-400, 1992.

BEWLEY, J. D.; BLACK, M. Seeds: physiology of development and germination. New York: Plenum, 1985. $367 \mathrm{p}$.

BRACCINI, A. L.; REIS, M. S.; SEDIYAMA, C. D.; ROCHA, V. S.; SEDIYAMA, T. Influência do processo de hidratação-desidratação na qualidade fisiológica de sementes de soja durante o armazenamento. Revista Brasileira de Sementes, Brasília, v. 19, n. 1, p. 80-87, 1997.

BRASIL. Ministério da Agricultura. Regras para análise de sementes. Brasília: Secretaria Nacional de Defesa Agropecuária, 1992. 365 p.

CLARKSON, D. T. Factors affecting mineral nutrient acquisition by plants. Annual Review of Plant Physiology, Palo Alto, v. 36, p. 77-115, 1985.

EMBRAPA. Serviço Nacional de Levantamento e Conservação de Solos (Rio de Janeiro, RJ). Manual de métodos de análise do solo. Rio de Janeiro, 1979. 58 p.

GRAHAM, P. H.; ROSAS, J. C. Phosphorus fertilization and symbiotic nitrogen fixation in common bean. Agronomy Journal, Madison, v. 71, n. 6, p. 925-926, 1979.

ISRAEL, D. W. Investigation of the role of phosphorus in symbiotic dinitrogen fixation. Plant Physiology, Rockville, v. 84, n. 3, p. 835-840, 1987.
JACOB-NETO, J.; ROSSETTO, C. A.V. Concentração de nutrientes nas sementes: o papel do molibdênio. Ciência \& Floresta, Seropédica, v. 5, n. 1, p. 171-183, 1998.

JONES JUNIOR, J. B. A guide for hydroponics and soilless culture grower. Beaverton: Timber, 1983. 124 p.

MALAVOLTA, E.; VITTI, G. C.; OLIVEIRA, S. Avaliação do estado nutricional das plantas. Piracicaba: Associação Brasileira para a Pesquisa da Potassa e do Fósforo, 1989. $944 \mathrm{p}$.

MARCOS FILHO, J.; CÍCERO, S. M.; SILVA, W. R. Avaliação da qualidade das sementes. Piracicaba: Fealq, 1987. $230 \mathrm{p}$.

MICHEL, B. E.; KAUFMANN, M. R. The osmotic potential of polyethyleneglycol 6000. Plant Physiology, Lancaster, v. 51, n. 6, p. 914-916, 1973.

POLLOCK, B. M. Vigor of garden bean seeds and seedlings influenced by initial seed moisture, substrate, oxygen, and imbibition temperature. Journal of the American Society for Horticultural Science, Alexandria, v. 51, n. 1, p. 577-584, 1969.

POWELL, A. A. Cell membrane and seed leachate conductivity in relation to the quality of seed for sowing. Journal of Seed Technology, East Lansing, v. 10, n. 2, p. 81-100, 1986.

ROSSETTO, C. A. V.; NOVEMBRE, A. D. L. C.; MARCOS FILHO, J.; NAKAGAWA, J. Comportamento das sementes de soja durante a fase inicial do processo de germinação. Scientia Agricola, Piracicaba, v. 54, n. 1/2, p. 106-115, 1997a.

RossetTO, C. A. V.; NOVEMBRE, A. D. L. C.; MARCOS FILHO, J.; NAKAGAWA, J. Efeito da disponibilidade hídrica do substrato, da qualidade fisiológica e do teor de água inicial das sementes de soja no processo de germinação. Scientia Agricola, Piracicaba, v. 54, n. 1/2, p. $97-105,1997 b$.

SANTOS, V. L. M.; CALIL, A. C.; RUIZ, H. A.; ALVARENGA, E. M.; SANTOS, C. M. Efeito do estresse salino e hídrico na germinação e vigor das sementes de soja. Revista Brasileira de Sementes, Brasília, v. 14, n. 2 , p. 189-194, 1992.

SFREDO, G. H.; BORKET, C. M.; NEPOMUCENO, A . L.; OLIVEIRA, M. C. N. Eficácia de produtos contendo micronutrientes, aplicados via semente, sobre a produtividade e teores de proteína da soja. Revista Brasileira de Ciência do Solo, Campinas, v. 21, n. 1, p. 41-45, 1997.

Pesq. agropec. bras., Brasília, v. 37, n. 3, p. 385-392, mar. 2002 
TAO, K. J. Factors causing variation in the conductivity test for soybean seeds. Journal of Seed Technology, East Lansing, v. 3, n. 1, p. 10-18, 1978.

TEIXEIRA, M. G. Influência do conteúdo de fósforo da semente na nodulação do feijoeiro (Phaseolus vulgaris L.). Seropédica: UFRRJ, 1995. 205 p. Tese de Doutorado.

TEIXEIRA, M. G.; GUERRA, J. G. M.; ALMEIDA, D. L. de; ARAÚJO, A. P.; FRANCO, A. A. Effect of seed phosphorus concentration on nodulation and growth of three common bean cultivars. Journal of Plant Nutrition, New York, v. 22, n. 10, p. 1599-1611, 1999.

TILDEN, R. L.; WEST, S. H. Reversal of the effects of ageing in soybean seeds. Plant Physiology, Rockville, v. 77, n. 3, p. 584-586, 1985.
TRIGO, L. F. N.; PESKE, S. T.; GASTAL, M. F.; VAHL, L. C.; TRIGO, M. F. O. Efeito do conteúdo de fósforo na semente de soja sobre o rendimento da planta subseqüente. Revista Brasileira de Sementes, Brasília, v. 19, n. 1, p. 111-115, 1997.

WOODSTOCK, L. W. Seed imbibition: a critical period for successful germination. Journal of Seed Technology, East Lansing, v. 12, n. 1, p. 1-15, 1988.

ZANG, M.; NYBORG, M. E.; McGILL, W. B. Phosphorus concentration in barley (Hordeum vulgare L.) seed: influence on seedling growth and dry matter production. Plant and Soil, Dordrecht, v. 122, n. 1, p. 7983,1990 